\title{
Pat Morris Jones
}

\author{
Alan Craft $^{1}$ \\ ${ }^{1}$ The Royal Victoria Infirmary, New Castle-upon-Tyne
}

July 25, 2020

\section{Obituary PBC}

\section{Dr Pat Morris Jones}

Dr Morris Jones who was President of SIOP in 1980/81 died on March 162020 at the age of 87. She was one of the first doctors in the UK to specialise in the care of children with cancer and over her 40 year career from 1953 to 1993 she saw survival rates improve from cancer being mainly a fatal disease to one where there was a real chance of cure with more than half of children surviving. She was an only child ,born in Oswestry ,close to the border with Wales. She trained in medicine at the Royal Free Medical School in London and found her way to Manchester to specialise in paediatrics. There she came under the influence of Basil Marsden, a paediatric pathologist and Dr Dorothy Pearson a radiotherapist. In 1954 Marsden had established the world's first population based children's malignant disease registry which became a prototype for registries all over the world. Dr Pearson was a founding member of SIOP and its second president. In the late 50 s and early 60 s the only real treatments available were surgery and radiotherapy but the emerging success of chemotherapy pioneered in the US, France and Germany led to a need for paediatricians to sub specialise in paediatric oncology. By the time Pat became involved the antagonism towards giving children chemotherapy had largely dissipated but how to use it to best advantage remained to be determined. She took up this challenge and built up one of the largest units in the UK. For many years she was single handed and absolutely dedicated to the care of children. She rarely took a day off. . Before people were talking about evidence based medicine she was adamant that treatment should be given in trials where we could learn what was best for the future. She was especially interested in Wilms' tumour and very involved in the Medical Research Council embryonal tumour group and in the MRC UKALL trials. In 1977 she helped found the UK Children's Cancer Study Group (UKCCSG) which eventually ensured that all children in the UK with cancer had access to the most up to date treatment. The early involvement of Manchester in the pre chemotherapy era using radiotherapy, and the registry, led her to take a real interest in the late effects of treatment. She had a collection of slides which she used to illustrate the late effects of radiotherapy when given to young children. Failure of skeletal growth could ensue from radiotherapy to growing bones and second malignancies occurred within radiation fields. She became heavily involved with Anna Meadows in Philadelphia in setting up the Late Effects Study Group which received substantial funding from NIH. This work was extended and has been perpetuated by Les Robison and his colleagues and has hugely influenced the design of clinical treatment protocols in recent years. She wrote an influential paper in 1990 entitled Childhood Cancer; Cure at what cost? In which she described the evolution of treatment for childhood cancer from one of cure at any cost to cure at least cost. Her fervent hope was that we would eventually get to a stage of cure at no cost. Pat was an inspirational teacher and leader and many of the young aspiring paediatric oncologists in the 70s turned to her for career advice and then once appointed to a post used her as a source of support and advice on patient management. She was most people's "phone a friend".

The psychosocial problems faced by both children and parents became much more obvious once potentially curative treatments were being used. Paradoxically parents seemed to be able to cope better with the near certainty of death of their child than with the possibility, but by no means certainty, of long term survival. 
She worked closely with Peter McGuire, a psychiatrist, and with social workers to define the problems faced by children and their families and devised interventions to try and help. It was clear from the early leukaemia trials, which involved cranial irradiation and brain tumours that endocrine insufficiency was a real problem and she worked closely with Professor Steve Shalet, a paediatric endocrinologist, to not only define what these problems were but also how to follow up and screen survivors. She was always much in demand for conferences once causing consternation in Bruges when, invited to take a shot at the men only archery club she hit the bull's eye first time. The local tradition was that anyone who did this was invited to become a member.

Her retirement at the age of 60 was marked by an enormous party in Manchester Town Hall attended by many of the patients whom she had successfully treated and the parents of many of those who had died. She remembered all of their names. She was short in stature but big in personality, loved clothes and is remembered for her leather skirts and red shoes. In later years her hair was often a shade of blue and always well coiffeured. She was always a straight talker and had lots to say in meetings. She was direct and always had strong opinions. She was once quoted in a national newspaper that money was being wasted on sending children to Disneyland.

Throughout her career she loved foreign travel which was often associated with scientific meetings. She built up a wide circle of friends including Anna Meadows, Dan D'Angio, Mark Nesbit and Audrey Evans whom she would call upon to offer training places to her aspiring young colleagues

When she retired from clinical work in 1993 she decided to move to London. "As a single lady why would I want to move into a country cottage? Soon after her move to central London she met and married her Italian hairdresser, Alfonso Cassarini, and enjoyed 20 blissful years travelling widely and exploring the capital's culture.

Pat Morris Jones was a forceful and formidable pioneer who always had the best interests of children and their families at the forefront of everything that she did. The incredible survival rates for children with cancer in the present era using treatments which are designed to minimise late effects are built on the shoulders of giants like her who dared to try.

Alan Craft

Tim Eden 


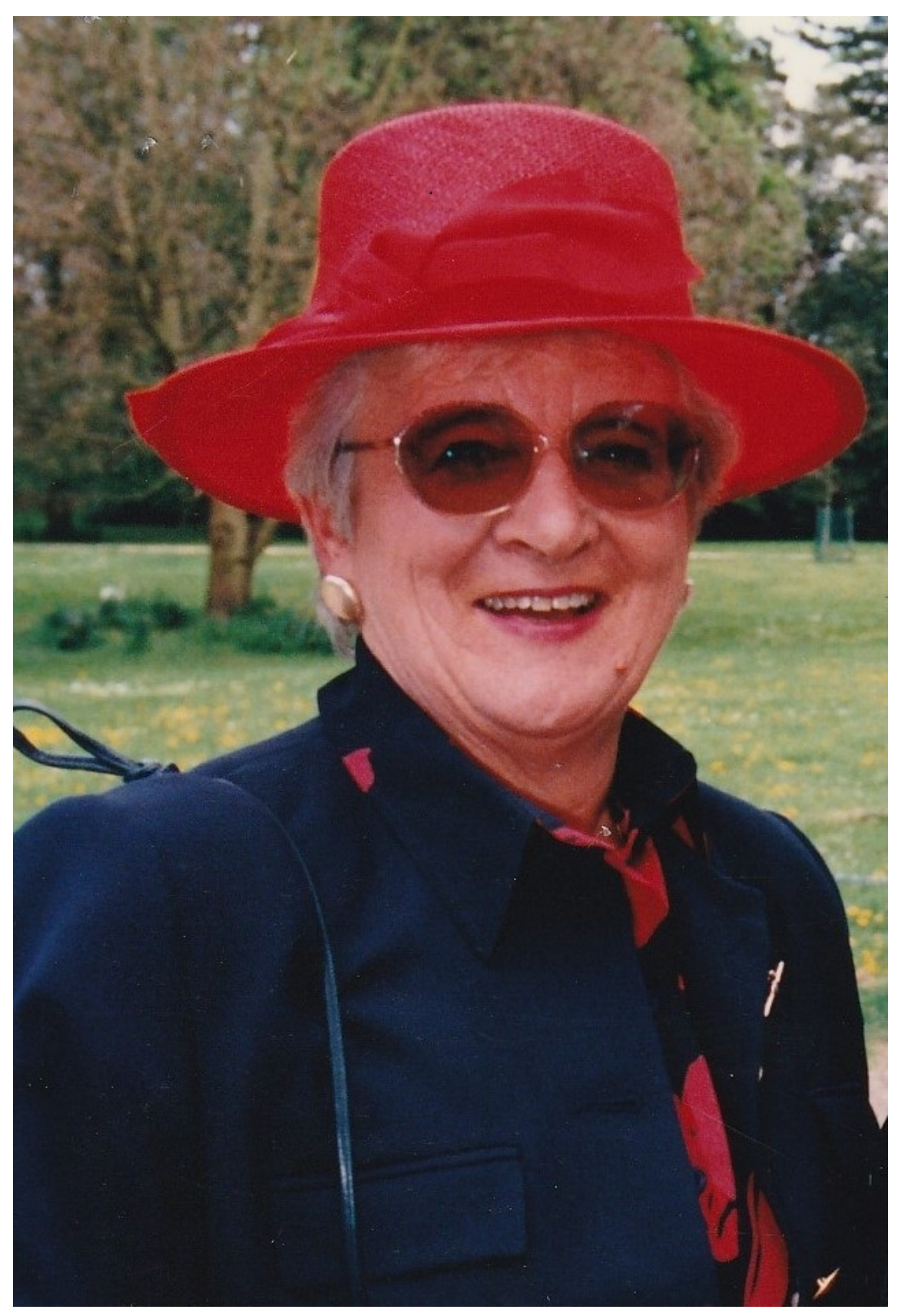

